\title{
Private finance for adaptation: do private realities meet public ambitions?
}

\author{
W. P. Pauw ${ }^{1,2,3}$ • R. J. T. Klein ${ }^{2}$ - P. Vellinga ${ }^{4} \cdot$ \\ F. Biermann ${ }^{3}$
}

Received: 23 July 2014 / Accepted: 22 October 2015 / Published online: 6 November 2015

(C) The Author(s) 2015. This article is published with open access at Springerlink.com

\begin{abstract}
The private sector's role in climate finance is increasingly subject to political and scientific debate. Yet there is poor empirical evidence of private engagement in adaptation and its potential contribution to the industrialised countries' mobilisation of USD 100 billion of annual climate finance from 2020 onwards to support developing countries to address climate change. This paper analysed 101 case studies of private sector adaptation under the Private Sector Initiative (PSI) of the UNFCCC Nairobi work programme, and examined these against ten 'adaptation finance criteria' that were distilled from UN climate negotiation outcomes. Results show that private adaptation interventions complement public adaptation activities. Yet the ten adaptation finance criteria are not met, which demonstrates that the diplomatic UNFCCC conceptualisation of financing adaptation is dissonant from the private sector reality. For example, while the case studies' investments are 'new and additional' to Official Development Assistance (ODA), their 'predictability' remains unclear. And despite some commitment for 'up-scaling', plans and associated costs for doing so remain undisclosed. Developed countries' role in 'mobilising' private financial resources under the PSI seems limited. It is unrealistic to expect that the UNFCCC alters existing criteria to suit private initiatives, or that the private sector aligns its initiatives to meet existing criteria. This paper advocates monitoring and reporting only of those private investments that principally finance adaptation. This practical way forward would allow private finance to meet criteria such as
\end{abstract}

Electronic supplementary material The online version of this article (doi:10.1007/s10584-015-1539-3) contains supplementary material, which is available to authorized users.

\section{W. P. Pauw}

w.p.pauw@gmail.com

1 Deutsches Institut für Entwicklungspolitik/ German Development Institute (DIE), Bonn, Germany

2 Stockholm Environment Institute, Stockholm, Sweden

3 Copernicus Institute of Sustainable Development, Utrecht University, Utrecht, The Netherlands

4 Institute for Environmental Studies (IVM), VU University, Amsterdam, The Netherlands 
predictability, transparency, and mobilisation, but would drastically reduce the amount of private investment that could contribute to reaching the USD 100 billion climate finance target.

\section{Introduction}

It is unequivocal that the climate is changing, and adaptation has become a core focus of climate policy (Berrang-Ford et al. 2014). Developing countries are historically least responsible for the emissions that result in climate change, but most vulnerable to its impacts (Ayers 2011), with costs of adaptation being estimated to be at least tens of billions of US Dollars per year (e.g., World Bank 2010; UNFCCC 2007a).

At the UNFCCC climate negotiation, developed countries recognized that substantially greater financial resources are needed to support both mitigation and adaptation in developing countries, and the 2009 'Copenhagen Accord' includes the goal of mobilizing USD 100 billion of climate finance per year from 2020 onwards (UNFCCC 2010). In this accord and the subsequent 2010 Cancun Agreements, both the public and the private sector are depicted as sources of climate finance.

Although climate finance has increased rapidly since Copenhagen, it is unclear whether the USD 100 billion target will be met from 2020 onwards. There is a growing body of literature that highlights private investments in mitigation, but there is little experience with private sector engagement in adaptation in developing countries (e.g., Buchner et al. 2011; Kato et al. 2014; UNFCCC 2007a). It is expected that the private sector will engage substantially in adaptation because it is in their interest to be climate resilient and to explore new business opportunities (e.g., ATKearney 2013; ICC 2009; Mendelssohn 2006; PwC 2010). Early conceptualisation of such engagement shows that it would include actors in all sectors and ranging all the way from smallholders and small enterprises to multinationals (c.f Pauw 2014). However, the actual evidence base is surprisingly poor (Fankhauser and Soare 2013) and does not allow for an assessment at sectoral or company level (Surminski 2013). Further conceptualisation of the role of the private sector in adaptation and its contributions to the USD 100 billion target should go hand in hand with the analysis of empirical data. For both UNFCCC negotiations and the Green Climate Fund's (GCF) engagement with the private sector (as an initial portfolio target) it is a crucial question to what extent private investments in adaptation could contribute to adaptation finance for developing countries.

This paper therefore analyses the 101 case study submissions to the Private Sector Initiative (PSI) of the UNFCCC Nairobi work programme on impacts, vulnerability and adaptation to climate change (NWP). This is currently the only large database of private sector engagement in adaptation, and is, consequently, often referred to in research (e.g., PwC 2010; Kato et al. 2014; Pauw and Pegels 2013; Surminski 2013). The case studies represent private adaptation interventions all over the world and in all sectors (e.g., water, food and agriculture; transport and infrastructure; tourism). Most case studies are implemented by multinationals such as Allianz, Anglo American, GlaxoSmithKline, Nestlé and Siemens, with less representation by small to medium sized enterprises (e.g., Banka Bioloo, Ignita), research institutes (Acclimatise, Ecofys), non-profit organisations (EWV, Fonkoze) and public-sector owned companies (Network Rail, ÖBB $)^{1}$. Although these case studies do not report on financing adaptation in the context of the USD 100 billion goal, the connection is clear. UNFCCC discussions on adaptation finance are indirectly influenced by activities under the NWP (Persson et al. 2009); and financing is an unofficial but integral part of adaptation under the NWP and an implicit

\footnotetext{
${ }^{1}$ For an overview, please see the Electronic Supplemental Material
} 
interest of the PSI. The UNFCCC highlights 'the unique expertise of the private sector, its capacity to innovate and produce new technologies for adaptation, and its financial leverage (...)' as a basis for cooperation. The PSI was launched in 2010 and as an online platform for businesses to contribute to adaptation in their operations and, 'importantly, in those of the most vulnerable countries and communities around the world' (UNFCCC 2014).

In doing so, the PSI - and therefore this paper- follows the definition of adaptation of the IPCC's Fourth Assessment Report: 'initiatives and measures to reduce the vulnerability of natural and human systems against actual or expected climate change effects' (UNFCCC 2014).

This paper analyses the extent to which the PSI case studies meet the UNFCCC's expectations on adaptation finance. These expectations are based on political framing for global adaptation finance and are not intended to measure adaptation effectiveness. The next section first distills ten criteria from the UNFCCC Copenhagen Accord and the Cancun Agreements, then defines them based on literature, and finally translates them into a private sector context as a framework for analysis of the PSI case studies. Results on the extent to which the PSI case studies meet these ten criteria are provided in section 3. Section 4 concludes and discusses ways forward.

\section{Adaptation finance criteria}

\subsection{UNFCCC context}

Ten criteria for adaptation finance were identified: adequate; predictable; sustainable; scaled up; new and additional; provided with improved access; balanced allocation between adaptation and mitigation; prioritized to the most vulnerable developing countries; mobilized by developed countries; and transparent (as explained below). We propose that private adaptation interventions, regardless of how good or successful they are, have to meet all ten criteria in order to be counted as part of the annual USD 100 billion of climate finance target.

These criteria are based on two milestones in international negotiations on climate finance: the Copenhagen Accord and its formalisation in the Cancun Agreements. The Copenhagen Accord declared to scale up climate finance for developing countries with USD 30 billion of fast-start finance for the period 2010-2012 and with USD 100 billion per year from 2020 onwards; declares the private sector as one of sources thereof; and initiated discussions on the (then 'Copenhagen') GCF. The Copenhagen Accord itself is a non-binding political declaration that lacks consensus among parties. The Cancun Agreements are included in this paper because they transform much of the Copenhagen Accords' content on climate finance into a decision of the Conference of the Parties (COP).

Some of these criteria are partly based on longer-standing work agreements under the UNFCCC. Criteria such as 'new and additional', 'adequacy' and 'predictability' have been articulated repeatedly, including in Article 4.3 of the 1992 Convention text (Müller 2008). In addition, the UNFCCC articulated more general requirements, including cost-effectiveness and efficiency of financing, and integrated approaches (see Horstmann and Chandani 2011). For climate action -only potentially including finance- the Copenhagen Accord includes the additional criteria 'country-driven approach' and 'based on national circumstances and priorities' (UNFCCC 2010; §11). Researchers and climate funds also proposed supplementary criteria, for example for feasible, effective and efficient adaptation finance (e.g., van Drunen et al. 2009; Müller 2008). However, this paper examines the extent to which the PSI case studies meet international adaptation finance criteria of the UNFCCC - not their effectiveness or efficiency. 


\subsection{Private Sector Initiative}

Private Sector Initiative (PSI) case studies descriptions are only 2-5 pages in length, which sometimes compromises the level of detail ${ }^{2}$. They are based on a common template which does not reflect the adaptation finance criteria. In order to maximise data collection, it was therefore decided only to do a qualitative analysis, and to provide descriptive statistics wherever possible. The PSI database is attractive for the analysis because of its uniqueness in providing case studies on private sector adaptation; its size $(N=101)$; and its association with UNFCCC processes. Furthermore, the case study descriptions' are comparable (same template) and publicly accessible at the UNFCCC website. Although a part of the case studies takes place in developed countries (i.e., not climate finance target countries), they were not excluded from the analysis a priori, for two reasons. First, many private actors in the PSI operate internationally, so case studies in developed countries could be replicated in developing countries. Second, the authors wanted to exploit the full potential of the database, and consider it as a function of the adaptation finance criteria to exclude incompatible case studies. Nevertheless, 16 case study descriptions were excluded because they advertised an adaptation product or service, without clarifying whether it was already (partly) implemented. Occasionally, more case studies were excluded if sufficiently detailed information was lacking.

Companies often implement case studies with a partner (58\%, three quarters of which with a public entity), yet participate voluntarily and submit their own case studies. Their benefits are possibilities to participate in activities mandated under the NWP; network opportunities; reputational advantages and increased visibility; and association with UNFCCC processes (UNFCCC 2014). The voluntary self-submission has three limitations. First, it might cause positively biased communication. This analysis is however not misguided by overly positive descriptions: it does not look at adaptation effectiveness but rather at the general nature of private engagement and the extent to which this meets the adaptation finance criteria. Second, voluntary self-reporting might limit the quality of submissions, particularly their level of detail. This issue, too, would be more pressing if this analysis would focus on adaptation effectiveness rather than the climatenegotiations related discussion on private sector engagement in adaptation. Third, the database does not represent the entire private sector. For example, 'Water resources' (52\% of all case studies) and 'Food security, agriculture, forestry, fish' (45\%) are probably overrepresented, whereas tourism (7\%) might be underrepresented ${ }^{3}$. Furthermore, companies that 'wait and see' - those having a strategy of deferral towards climate change impacts - and those that 'share and shift' risks through insurance and collaboration (Berkhout et al. 2006; 151) are unlikely to submit a case study. The dataset is thus skewed towards companies with clear interests in climate change: frontrunners and companies that are closest to UNFCCC processes.

\subsection{Explaining the Adaptation finance criteria}

This section defines the individual criteria based on climate finance literature including AGF (2010), ActionAid (2007), Christiansen et al. (2012); van Drunen et al. (2009), Horstmann and Chandani

\footnotetext{
${ }^{2}$ Almost all case studies (98\%) refer to websites for more information. However, 12 links were not working, three referred to non-English websites; and 30 referred to (company) homepages, instead of dedicated project websites. Altogether, only 40 very dissimilar websites were screened as a secondary source of additional information.

${ }^{3}$ These are the categories from the PSI template. Case studies can fit under multiple categories (See also the Electronic Supplemental Material).
} 
(2011), Müller (2008) and AMCEN (2011) and supported by data from Climate Finance Update (2014). The definitions were verified by a climate finance expert from the UNFCCC Secretariat.

Although it would be interesting to apply these criteria on public climate finance too, this paper addresses private finance. For that purpose it translates each criterion in representative and analysable aspects of private adaptation under the PSI. The criteria are based on longerstanding country-based agreements under the UNFCCC and therefore reflect public perspectives on financing. This is most explicit for the criteria 'new and additional' and 'predictable', but is visible in other criteria as well. The research questions for the analysis of PSI case studies were therefore adjusted to reflect the private sector context.

1. Adequate. The Copenhagen Accord statement that developed countries shall provide adequate financial resources to support the implementation of adaptation action in developing countries (UNFCCC 2010; §3, §8) was formalised under a decision in the Cancun Agreements (UNFCCC 2011; §97). Adequate can be interpreted either in terms of amount or in terms of meeting adaptation needs. Literature generally interprets 'adequacy' in terms of the former. For example, ActionAid (2007), Müller (2008) and Christiansen et al. (2012) refer to the inadequacy of adaptation funding compared to the estimated costs. Indeed, van Drunen et al. (2009; 16-17) write that under the Convention, 'adequate (...) funds were meant to help developing countries meet the agreed full incremental costs'. This paper takes 'adequate' as sufficient financing to cover relevant adaptation costs in developing countries. To identify whether the private sector can contribute substantially to cover adaptation costs, case studies were analysed on mentioning climate finance, and providing cost estimates and (total) investments.

2. Predictable. The Copenhagen Accord statement that developed countries shall provide predictable financial resources to support the implementation of adaptation action in developing countries (UNFCCC 2010; §3, §8) was formalised under a decision in the Cancun Agreements (UNFCCC 2011; §97). The UNFCCC does not further define predictability. Predictable funding is crucial for developing countries to formulate adaptation strategies and implement activities (AMCEN 2011; AGF 2010). In development literature, the Accra Agenda for Action (2008) translates predictability into donor countries providing timely information on annual expenditure as well as rolling out three- to 5-year forward planning. This paper interprets 'predictability' not as changing amounts of funding, but on whether recipients can expect future adaptation finance. This paper thus analysed whether the PSI case studies describe their medium- to long-term planning, including indications of project duration, project extension and related costs.

3. Sustainable. The Copenhagen Accord states that developed countries 'shall provide sustainable financial resources (...) to support the implementation of adaptation action in developing countries' (\$3). Although the 'sustainable criterion' was not formalised in the Cancun agreements, it is still discussed in international climate finance debates and therefore included in this paper. For example, sustainability has been a major issue in discussions on climate finance bridging the period between fast-start finance (2010 2012) and the annual USD 100 billion (from 2020 onwards). Climate finance literature does not further define 'sustainable' finance. Given that climate finance should increase to USD 100 billion per year (UNFCCC 2011), this paper distinguishes it from predictability by operationalising it as the amount of adaptation finance staying the same or increasing over time. The PSI case studies are thus analysed on 1) mentioning stable or increasing investment volumes; or that 2) case studies generate revenues that allow for 
perpetual investments. In a broader sense, the paper also analysed whether case studies describe lasting impacts of interventions.

4. Scaling up. The Copenhagen Accord states that 'Scaled up (...) funding (...) shall be provided to developing countries (UNFCCC 2010; §8), which is formalised in a decision in the Cancun Agreements (UNFCCC 2011; §97). How fast or by how much is however not defined. The increase from USD 30 billion over the period 2010-2012 (i.e., on average USD 10 billion per year) to USD 100 billion per year from 2020 onwards would be a ten-fold increase. The private sector does not think of scaling up in terms of increasing budgets, but rather in terms of increasing revenues from a proven business model, or reducing marginal costs. This paper thus identifies possibilities and plans for scaling up and replication as described in the PSI case studies, including adaptation benefits in terms of cost-reductions or market opportunities.

5. 'New and additional'. In the Copenhagen Accord, developed countries make the collective commitment to provide new and additional resources approaching USD 30 billion for the period 2010-2012 (UNFCCC 2010; §8). In the Cancun agreements (UNFCCC 2011), and also relating to the 'scaling up' criterion, the COP decides that new and additional funding shall be provided (\$97), but only takes note of the idea that these 'new and additional' resources shall approach USD 30 billion for the period 20102012 (\$95). 'New and additional' relates to official development assistance (ODA), meaning climate finance should be over and above existing traditional development funding (van Drunen et al. 2009). This paper analyses whether ODA was used to cofinance the PSI case studies.

6. Improved access. The Cancun Agreements do not reiterate the Copenhagen Accord's statement that: '(...) funding as well as improved access shall be provided to developing countries' (UNFCCC 2010; §8). Nevertheless, improved access is a criterion in this analysis: it is still debated upon during UNFCCC climate negotiations and is a key concept in the design of the GCF (see also UNFCCC 2011; Green Climate Fund 2014). The ultimate goal of improved access is to reach the most vulnerable people. According to Ayers (2011), vulnerability to the global risk of climate change is locally experienced, which she calls the 'adaptation paradox'. Current governance of funding relationships is often accountable to contributors of climate finance rather than to the most vulnerable people that experience climate change impacts locally (ActionAid 2007). Rather than assessing improved access to climate finance by the most vulnerable people, which is impossible in the context of the PSI, this paper interprets 'improved access' as to whether those who would experience climate change impacts locally access the benefits of the case studies. The paper thus analysed whether case studies' interventions have external benefits; and whether these benefits reach those individuals who experience local impacts of climate change.

7. Balanced allocation. In the Copenhagen Accord the developed countries make a collective commitment to provide 'resources (...) with balanced allocation between adaptation and mitigation’ (UNFCCC 2010; §8). The Cancun Agreements only ‘takes note' on this (UNFCCC 2011; §95), and also state that adaptation must be addressed with the same priority as mitigation (UNFCCC 2011; §2). It is, however, not further defined what a 'balanced' allocation means. In both the Copenhagen Accord and the Cancun Agreements, 'balancing' only refers to the period 2010-2012. However, COP decision 3/CP.17 reiterates a balanced allocation in a request for the future GCF board, which indeed decided to 'aim for a 50:50 balance between adaptation and mitigation 
during the initial phase of the Fund' (Green Climate Fund 2014; 6). According to Climate Finance Update (2014) around $16 \%$ of the public climate finance flows to adaptation so far. Whether this should increase to $50 \%$ is an open question, but in any case the finance for adaptation needs to increase (Halimanjaya 2014). The amount of private adaptation finance is very hard to track but seems minimal compared to private mitigation finance (Buchner et al. 2011). 'Balanced allocation' could however not be part of the analysis, as the PSI only includes case studies on adaptation (with a few having some mitigation co-benefits).

8. Prioritization. The Copenhagen Accord states that adaptation funding will be prioritized for the 'most vulnerable developing countries, such as the least developed countries (LDCs), small island developing States (SIDS) and Africa' (UNFCCC 2010; §8). The Cancun Agreements only take note of this (UNFCCC 2011; §95). Climate funds such as the Global Climate Change Alliance, the Pilot Project on Climate Resilience and the Adaptation Fund were all designed to make decisions on country prioritisation and allocate funds based on levels of vulnerability, but they all have their own standards for doing so (Klein and Möhner 2011). Altogether it remains unclear what 'prioritization' means in terms of, for example, financing or effort, so the author looked at actual flows. Of the total public adaptation finance that was approved so far, Climate Finance Update (2014) estimates that $32 \%$ flowed to Africa, $52 \%$ to LDCs, and $9 \%$ to SIDS. Given the overlap, this means $60 \%$ flows to the UNFCCC's 'most vulnerable developing countries'. This hardly reflects a country-based prioritisation, considering that these three groups together constitute 94 out of $140+$ developing countries ${ }^{4}$, and that $22 \%$ of these 94 countries have not received public climate finance so far. A prioritization based on a per capita basis would have very different outcomes, with Asia more central. However, this paper analyses along UNFCCC outcomes and thus prioritizes based on countries in which PSI case studies were implemented. For reasons of practicality, it installs a $60 \%$ threshold based on the analysis of Climate Finance Update.

9. Mobilizing. In the Copenhagen Accord, developed countries commit to a goal of mobilizing jointly USD 100 billion dollars per year by 2020 to address the needs of developing countries (UNFCCC 2010; §8). The COP only 'recognizes' this goal in the Cancun Agreements (\$98). A definition of 'mobilizing' was not found. This paper interprets it broadly as pro-active public interventions of developed countries that increase public and private financing of adaptation or mitigation in developing countries. This goes beyond domestic mobilisation of climate finance and includes institution building; enhancing climate finance readiness in developing countries; and the creation of incentives to increase private investments. To identify whether the PSI case studies' interventions are 'mobilised', this paper analysed whether developed country institutions were involved in the planning and implementation, and whether public policies and cofinancing are mentioned, both in developed and developing countries in order to allow for a broader overview.

10. Transparency. in the Copenhagen Accord, transparency is mentioned in the context of 'meaningful mitigation' and the mobilisation of USD 100 billion dollars per year by 2020 to address the needs of developing countries (UNFCCC 2010; §8). The Cancun Agreement only 'recognizes' this (UNFCCC 2011; §98). Transparency is broader in

\footnotetext{
4 'Developing countries'is not an official group under the UNFCCC. However, as a comparison: there are 154 non-Annex I parties (see http://unfccc.int/parties_and_observers/parties/non_annex_i/items/2833.php).
} 
literature. For example, ActionAid (2007) suggest that transparency goes beyond purposes (i.e., mitigation), amounts (i.e., USD 100 billion per year), and results of funding (i.e., meaningful), but also includes the governance structure and procedures at providers of financial resources. Klein (2011) points out that transparency means different things depending on whether you look at generation, governance, delivery, or use of finance. The Adaptation Fund indeed introduced transparency indicators in its overall management (Horstmann and Chandani 2011). Eventually, transparency on climate finance also means monitoring, reporting, and verification and tracking climate finance from source to final use (Buchner et al. 2011; van Drunen et al. 2009). To operationalise 'transparency' in a private sector context, this paper analysed whether the case studies describe investments and discusses how they are generated, governed, delivered and used.

\section{Results}

Some case study descriptions cause doubts on whether they deliberately aim at adaptation, or 'accidentally' contribute to it. Only $53 \%$ of the case studies describe climate change impacts. Five case studies descriptions do not even mention climate change, and none of the case studies defines a concept of adaptation. However, this paper does not analyse the adaptation results or effectiveness but rather looks at the nature of private engagement and the extent to which this meets the ten adaptation finance criteria. In the text below, they are categorised in three groups:

- Amount of finance (criteria: adequate, predictable, sustainable, scaled-up)

- Recipients of investments (criteria: improved access, prioritization)

- Overarching criteria (criteria: mobilization, new and additional, transparency).

\subsection{Amount of finance}

Adequate None of the case studies mentions 'climate finance'. Seven case studies (8\%) provided cost estimates, six of which were in developing countries, with budgets ranging from USD 3 million (PepsiCo) to approximately USD 516 million (Nestlé). This does not seem adequate as it is very little compared to the estimated needs of at least tens of billions US Dollars per year in developing countries. Yet the PSI case studies only represent a fraction of the international private sector's contributions to adaptation. Adaptation-related investments can thus be expected to be significant, but the PSI case studies do not allow for a conclusion on adequacy.

Only 22 case studies indicate how long projects run, indicating a low predictability. These are mostly longer-term projects - on average they last 80 months (standard deviation: 64.2), with the longest already running since 1993, and the shortest having a 12 month duration. Only 10 case studies explicitly mention project extension. At least ten more projects hint at it, and extension of more case studies can be expected. For example, almost $60 \%$ of the cases are carried out with a partner. As Kato et al. (2014) show, this helps to stimulate replication and scaling up, in particular where projects were successful. This feeds in the discussion on the criterion 'sustainability'. A variety of case studies emphasize the importance of project sustainability, including for proactive protection of public water supplies and the environment in the United Kingdom to reduce costs (Thames Water), and cyclone-proof reconstruction of schools in Madagascar (CBRE and UNICEF). Others do not mention it explicitly, but could 
have lasting impacts through hard adaptation interventions (e.g., construction work or irrigation equipment) or soft adaptation (e.g., training and capacity building). However, only 16 case studies explicitly describe the sustainable continuation of the project itself.

Thirteen case studies (plan to) scale up their project, half of which in the UNFCCC's 'most vulnerable developing countries'. It must be noted that some case studies cannot be scaled up. For example, just like Thames Water (see above), Network Rail identified climate risks and adaptation responses, in this case for the railway network in the United Kingdom. Such assessments could be deepened or replicated elsewhere, but not scaled up. Scaling up would rather concern the implementation of those plans, but it is unlikely that this is financed through the same budget. The case studies that plan scaling up provide little information on how to do this, but the OECD analysed two of them in more detail. First, BASIX and ICICI Lombard increased the sale of index-based weather insurance contracts to small-scale farmers in India from 230 in 2003 to over 12 million in 2014; and replication is ongoing in a number of countries (Kato et al. 2014). Second, Cafédirect's case study of assisting farmers to make their coffee production more climate-resilient has been replicated to a number of producer organisations in other developing countries, both by Cafédirect and the initial project partner Gesellschaft für Technische Zusammenarbeit (GTZ) (ibid).

Many case studies also mention market and job-creation opportunities or opportunities to reduce future risks and costs of climate change, both of which increase potential for scaling up. Of all case studies, $46 \%$ mainstream adaptation into their operations (e.g., reducing water use or securing a supply-chain), and $35 \%$ describes new market opportunities (e.g., selling adaptation products and planning services). Activities that include both mainstreaming and capitalizing on new business opportunities, such as the insurance product by BASIX and ICICI Lombard, are mentioned by $19 \%$ of the case studies.

To conclude, the private sector invests in adaptation, including in developing countries, but the amount and predictability of investments remains unclear. A share of the case studies show commitment to sustainability and scaling up. Yet plans are not described in detail. Also, it is unclear to what extent sustainable project implementation and scaling up of projects translates in sustainable and scaled up financing.

\subsection{Recipients of investments}

Prioritization The case studies cover the entire world, with 22 projects in Europe and 18 North America; 27 in Africa and Arab States, and 28 in Asia ${ }^{\text {ii }}$. However, there is no prioritization towards the UNFCCC's 'most vulnerable developing countries': 14 projects take place in LDCs, four in SIDS, and 17 in Africa. Given the overlap between these groups, only a third of the 85 case studies take place in the most vulnerable developing countries. This might reflect the difficult business environment and low preparedness for private sector adaptation in these countries (Pauw and Pegels 2013), or a lower awareness of the PSI among companies in developing countries. Also, the NWP's objective is to assist developing countries in particular, including the LDCs and SIDS (UNFCCC 2007b) - which is different from 'prioritizing' LDCs, SIDS and Africa.

Improved access Seventy-nine per cent of the case studies $(N=81)$ explicitly articulate external adaptation benefits, which means communities, other firms or governments benefit from the private investment in adaptation. Some have direct positive influences on livelihoods, 
for example though improved water availability or increased agricultural output. Other are minor side-benefits only, such as climate-resilient rail tracks (comforting travellers - thus also ensuring customers) or new hiking paths where glaciers retreated (benefitting hikers potentially attracting more tourists). An adaptive measure like wetland restoration can have both positive effect on livelihoods (some case studies emphasise improved natural resource management) or be a minor side-benefit only (one case describes the 'natural amenity' for local inhabitants).

Only 22 case studies indicate how long projects run, indicating a low predictability. These are mostly longer-term projects - on average they last 80 months (standard deviation: 64.2), with the longest already running since 1993, and the shortest having a 12 month duration. Only 10 case studies explicitly mention project extension. At least ten more projects hint at it, and extension of more case studies can be expected. For example, almost $60 \%$ of the cases are carried out with a partner. As Kato et al. (2014) show, this helps to stimulate replication and scaling up, in particular where projects were successful. This feeds in the discussion on the criterion 'sustainability'. A variety of case studies emphasize the importance of project sustainability, including for proactive protection of public water supplies and the environment in the United Kingdom to reduce costs (Thames Water), and cyclone-proof reconstruction of schools in Madagascar (CBRE and UNICEF). Others do not mention it explicitly, but could have lasting impacts through hard adaptation interventions (e.g., construction work or irrigation equipment) or soft adaptation (e.g., training and capacity building). However, only 16 case studies explicitly describe the sustainable continuation of the project itself.

Thirteen case studies (plan to) scale up their project, half of which in the UNFCCC's 'most vulnerable developing countries'. It must be noted that some case studies cannot be scaled up. For example, just like Thames Water (see above), Network Rail identified climate risks and adaptation responses, in this case for the railway network in the United Kingdom. Such assessments could be deepened or replicated elsewhere, but not scaled up. Scaling up would rather concern the implementation of those plans, but it is unlikely that this is financed through the same budget. The case studies that plan scaling up provide little information on how to do this, but the OECD analysed two of them in more detail. First, BASIX and ICICI Lombard increased the sale of index-based weather insurance contracts to small-scale farmers in India from 230 in 2003 to over 12 million in 2014; and replication is ongoing in a number of countries (Kato et al. 2014). Second, Cafédirect's case study of assisting farmers to make their coffee production more climate-resilient has been replicated to a number of producer organisations in other developing countries, both by Cafédirect and the initial project partner Gesellschaft für Technische Zusammenarbeit (GTZ) (ibid).

Many case studies also mention market and job-creation opportunities or opportunities to reduce future risks and costs of climate change, both of which increase potential for scaling up. Of all case studies, $46 \%$ mainstream adaptation into their operations (e.g., reducing water use or securing a supply-chain), and $35 \%$ describes new market opportunities (e.g., selling adaptation products and planning services). Activities that include both mainstreaming and capitalizing on new business opportunities, such as the insurance product by BASIX and ICICI Lombard, are mentioned by $19 \%$ of the case studies.

To conclude, the private sector invests in adaptation, including in developing countries, but the amount and predictability of investments remains unclear. A share of the case studies show commitment to sustainability and scaling up. Yet plans are not described in detail. Also, it is unclear to what extent sustainable project implementation and scaling up of projects translates in sustainable and scaled up financing. 


\subsection{Overarching themes}

Mobilizing; new and additional Eight case studies explicitly state that the government or its policies influenced project plans or outcomes. For example, in the Indian Kashmir region with its unpredictable climate, the cooperative 'Fasiam Agro Farms' helps farmers to switch from maize to low-risk, high-value aromatic and medicinal crops, and to process and market these. The Indian government supported and co-financed Fasiam Agro Farms. Multinational mining company Anglo-American states to closely follow the government's mine closure and rehabilitation strategy whilst developing its US\$ 100 million water reclamation plant.

Another 17 projects were implemented under public-private cooperation. Case studies in developing countries with developed-country partner institutions are particularly important in the context of international adaptation finance. However, development banks and -agencies are involved in a few case studies only, and with very different roles. Kato et al. (2014) again provide insight on two case studies. GTZ provided technical support and co-financed the adaptation project with Cafédirect in a variety of developing countries; and the World Bank provided technical support to establish the weather-risk based insurance in India. When considering all case studies, the participation of public entities from developed countries is not transparent but seems limited, which means that the PSI investments are new and additional to ODA.

Transparency Only seven case studies ( $8 \%$ ) provided cost estimates (see 'adequacy'). Details on generation of finance, its governance, delivery, or use are not provided. The case studies' web links provide similar information on costs of an additional five case studies only. One explanations for this lack of detail is the short PSI template: it neither requires budget information, nor allows for extensive explanations of investments. Another explanation is that firms operate in a competitive environment: not being transparent might be a strategic decision (Kato et al. 2014). This would mean that imposing UNFCCC transparency standards might reduce private sector appetite to engage in international adaptation finance.

To summarize, it is likely that most private adaptation finance under the PSI is new and additional to ODA, but there is a general lack of transparency on costs and financing. Public institutions active in climate finance only partner in a limited number of case studies, but their exact role often remains unclear.

\section{Conclusion and way forward}

This paper first distilled ten criteria for adaptation finance from the Copenhagen Accord and subsequent climate negotiations, and highlighted that these criteria only have vague and nonofficial definitions. It then analysed to what extent the PSI case studies meet these criteria, as a proxy to whether the private sector could take over adaptation finance responsibilities under the developed countries' pledge at the UNFCCC to mobilize USD 100 billion of climate finance per year from 2020 onwards.

The PSI case studies on private sector adaptation confirm the idea (e.g., Fankhauser and Soare 2013; Mendelsohn 2006; Pauw 2014) that the private sector actively engages in adaptation, often without public support of any kind; and that it complements public adaptation activities on the ground including in priority sectors such as water and agriculture.

However, the analysis of 101 PSI case studies shows that not all private sector contributions to adaptation also contribute to international adaptation finance (see Fig. 1). Only a minority of 
Types of private sector engagement in adaptation

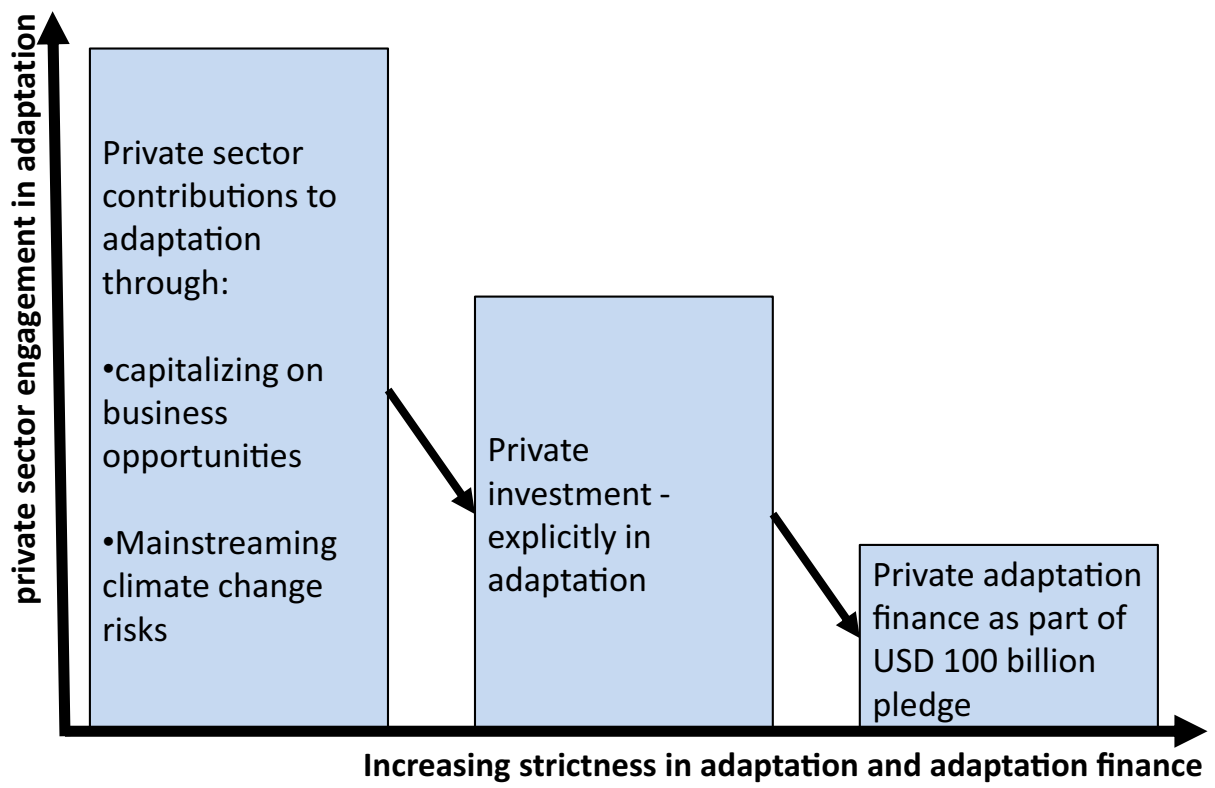

Fig. 1 Private sector engagement in climate change adaptation plotted against increasingly strict conceptualisations of adaptation and adaptation finance

the case studies takes place in the 'prioritised' most vulnerable developing countries. Private investments of the PSI case studies are 'new and additional' to ODA, but their 'adequacy' and 'predictability' remain unclear. And although some case studies commit to 'sustainability' and 'scaling up', the actual plans and their associated investments remain undisclosed. As for 'improved access': most case studies have external benefits, including for those most vulnerable in developing countries. This does not mean they have ownership or improved access to finance, but it shows that the international private sector can contribute to adaptation of some of the people most vulnerable to climate change. The case studies showed little evidence of being 'mobilised' by developed countries. A better insight in the role of the private sector in adaptation finance would definitely require more 'transparency' on generation, governance, delivery and use of finance. An analyses of the exact extent to which the case studies meet the ten adaptation finance criteria would require more in-depth research, for example through interviews, site-visits and an analysis of (classified) project documentation.

Public and private sectors have different motivations to invest in adaptation (c.f. Pauw 2014). This paper adds that the diplomatic UNFCCC conceptualisation of financing adaptation is dissonant from the private sector reality. Even the PSI case studies on adaptation potentially positively biased, dominated by frontrunners, and 'associated' with UNFCCC processes do not come close to meeting the ten adaptation finance criteria. Three approaches could be thought of to improve this situation and to better examine whether private investments could qualify as international adaptation finance as negotiated under the UNFCCC.

First, the UNFCCC could alter existing criteria to make them more suitable for private initiatives. Subsequently, the adaptation agenda -already burdened with conceptual issues such as the 'adaptation paradox' (Ayers 2011) and the complex relation between adaptation and 
development (e.g., Huq and Reid 2004; Persson and Klein 2009) - would be broadened even further. The PSI database shows a wide variety of sectors, type of private actors, modes of cooperation and projects that would need to be accommodated. Financing instruments would come on top of that. UNFCCC Parties would have to agree on a new set of all-encompassing criteria allowing for accountability, but it is unlikely that they reach consensus. Criteria have not been further defined in the past because of the political process and the difficulties in reaching agreement (Klein and Möhner 2011). Furthermore, developing country parties often voice their general scepticism towards private finance for adaptation. Future research could however provide an impulse here, for example through an analysis on whether public adaptation finance itself meets the ten adaptation finance criteria, or by providing a clear (e.g., resilience-based instead of adaptation-based) framework for private adaptation finance.

Second, the private sector could increase its effort to understand UNFCCC outcomes, and adaptation finance criteria in particular, in order to align their investments and communication. This paper shows that this does not happen naturally, despite existing private sector interest and experiences with adaptation and their presence at COPs (Hanegraaff 2015). The public sector has dedicated adaptation funds to contribute to the USD 100 billion target. Yet for the private sector, adaptation is often mainstreamed in other activities (Berkhout et al. 2006; Pauw 2014). Businesses are probably not intrinsically motivated to artificially separate adaptation just to comply with (complex) UNFCCC reporting procedures. Disclosure of commercial confidentiality is another barrier. There are however forums in which the private sector committed to voluntary reporting, such as the Carbon Disclosure Project and the Equator Principles. As a try-out, some adaptation finance criteria or their derivatives could be added to the PSI case-study template. For example, explicitly requiring information about project duration, reaching out and inclusiveness would provide more insight in 'predictability' and 'improved access'. One precondition is a COP mandate to lift the PSI beyond a UNFCCC Secretariat 'initiative'. This would provide the political space and capacity to significantly change the template. Earlier changes were minimal and did not lead to significant differences in content. An improved template would also raise awareness and help future analysis of private adaptation interventions in the context of the USD 100 billion climate finance. Clearly, however, the biggest potential lies outside of the PSI, with thousands of companies worldwide contributing to adaptation.

Both approaches seem unrealistic. Picking the low hanging fruit is a third and more practical approach: only monitor and report private engagement in adaptation that principally planned to finance adaptation. This could for example be philanthropy or private finance that is mobilised through publicly financed adaptation projects and carried out by development banks and agencies. Mobilisation through public policies would not be part of this approach, as causes and effects are unclear. This third option dramatically thins out private adaptation finance that contributes to the USD 100 billion of climate finance, which means more public finance is needed to reach this annual target. However, it is a practical way forward in which private investments could meet criteria such as 'predictability', 'sustainability', 'transparency', and 'mobilisation'.

Open Access This article is distributed under the terms of the Creative Commons Attribution 4.0 International License (http://creativecommons.org/licenses/by/4.0/), which permits unrestricted use, distribution, and reproduction in any medium, provided you give appropriate credit to the original author(s) and the source, provide a link to the Creative Commons license, and indicate if changes were made. 


\section{References}

Accra Agenda for Action (2008) Accra agenda for action. 3rd High Level Forum on Aid Effectiveness. Accra ActionAid (2007) Equitable adaptation finance: the case for an enhanced funding mechanism under the UN Framework Convention on Climate Change. ActionAid International, Johannesburg

AGF (2010) Report of the secretary-general's high-level advisory group on climate change financing. United Nations, New York

AMCEN (2011) Addressing climate change challenges in Africa; a practical guide towards sustainable development. AMCEN secretariat, Nairobi

ATKearney (2013) Adapting to the inevitable. A.T.Kearney's foresight series, Thinkforward

Ayers J (2011) Resolving the adaptation paradox. Glob Environ Polit 11(1):62-88

Berkhout F, Hertin J, Gann DM (2006) Learning to adapt: organisational adaptation to climate change impacts. Clim Chang 78(1):135-156

Berrang-Ford L, Ford JD, Lesnikowski A, Poutiainen C, Barrera M, Heymann SJ (2014) What drives national adaptation? A global assessment. Clim Chang 124:441-450

Buchner B, Falconer A, Hervé-Mignucci M, Trabacchi C, Brinkman M (2011) The landscape of climate finance. Climate Policy Initiative, Venice

Christiansen L, Ray AD, Smith JB, Haites E (2012) Accessing international funding for climate change adaptation. UNEP Risø Centre on Energy, Climate and Sustainable Development, Roskilde

Climate Finance Update (2014) The data. http://www.climatefundsupdate.org/data

Fankhauser S, Soare R (2013) An economic approach to adaptation: illustrations from Europe. Clim Chang 118: 367-379

Green Climate Fund (2014) Initial modalities for the operation of the fund's mitigation and adaptation windows and its private sector facility. GCF/B.07/08

Halimanjaya A (2014) Climate mitigation finance across developing countries: what are the major determinants?. Climate Policy, (ahead-of-print), 1-30

Hanegraaff M (2015) Transnational advocacy over time: business and NGO mobilization at UN climate summits. Glob Environ Polit 15(1):83-104

Horstmann B, Chardani A (2011) The adaptation fund of the Kyoto Protocol: a model for financing adaptation to climate change? Climate Law 2(3):1-23

Huq S, Reid H (2004) Mainstreaming adaptation in development. IDS Bull 35(3):15-21

ICC (2009) ICC views on adaptation to climate change. Discussion paper. International Chamber of Commerce, Paris

Kato T, Ellis J, Pauw P, Caruso R (2014) Scaling up and replicating effective climate finance interventions. Climate Change Expert Group Paper No 2014(1). OECD and IEA, Paris

Klein RJT (2011) Show me the money: ensuring equity, transparency and accountability in adaptation finance. In: Transparency International (ed) Global corruption report: climate change. Earthscan, London, pp 220-233

Klein RJT, Möhner A (2011) The political dimension of vulnerability: implications for the Green Climate Fund. IDS Bull 42(3):15-22

Mendelssohn R (2006) The role of markets and governments in helping society adapt to a changing climate. Clim Chang 78:203-215

Müller B (2008) International adaptation finance: the need for an innovative and strategic approach. Oxford Institute for Energy Studies, Oxford

Pauw WP (2014) Not a panacea: private-sector engagement in adaptation and adaptation finance in developing countries. Clim Pol 15(5):583-604

Pauw WP, Pegels A (2013) Private sector engagement in climate change adaptation in the Least Developed Countries: an exploration. Climate Dev 5(4):257-267

Persson Å, Klein RJT (2009) Mainstreaming adaptation to climate change in official development assistance: challenges to foreign policy integration. In: Harris P (ed) Climate Change and Foreign Policy: Case Studies from East to West. Routledge, London, pp 162-177

Persson Å, Klein RJ, Siebert CK, Atteridge A, Müller B, Hoffmaister J, Lazarus M, Takama T (2009) Adaptation finance under a Copenhagen agreed outcome. Stockholm Environment Institute, Stockholm

PwC (2010) Business leadership on climate change adaptation. Encouraging engagement and action. London: Author

Surminski S (2013) Private sector adaptation to climate risk. Nat Clim Chang 3(11):943-945

UNFCCC (2007a) Investment and Financial Flows UNFCCC to address Climate Change. UNFCCC, Bonn

UNFCCC (2007b) The Nairobi work programme on impacts, vulnerability and adaptation to climate change. https://unfccc.int/files/adaptation/sbsta_agenda_item_adaptation/application/pdf/nwp_brochure.pdf 
UNFCCC (2010) Report of the Conference of the Parties on its fifteenth session, held in Copenhagen from 7 to 19 December 2009. http://unfccc.int/bodies/body/6383/php/view/reports.php. 08.07.2014

UNFCCC (2011) Report of the Conference of the Parties on its sixteenth session, held in Cancun from 29 November to 10 December 2010. http://unfccc.int/bodies/body/6383/php/view/reports.php. 08.07.2014

UNFCCC (2014) Adaptation Private Sector Initiative (PSI). http://unfccc.int/adaptation/workstreams/nairobi work_programme/items/4623.php. 08.07.2014

van Drunen M, Bouwer L, Dellink R, Gupta J, Massey E, Pauw P (2009) Financing adaptation in developing countries: assessing new mechanisms. Climate Change Scientific Assessment and Policy Analysis (NRPCC-WAB). PBL, Bilthoven

World Bank (2010) Economics of adaptation to climate change. Synthesis report. The World Bank, Washington 